\title{
Automatic detection and agronomic characterization of olive groves using high-resolution imagery and LIDAR data
}

\author{
Caruso T. ${ }^{1}$, Rühl J. ${ }^{1}$, Sciortino R. ${ }^{2}$, Marra F. P. ${ }^{1}$, La Scalia G. ${ }^{3}$ \\ ${ }^{1}$ Dipartimento Scienze Agrarie e Forestali, Università di Palermo, Facoltà di Agraria, Viale delle \\ Scienze Ed. 4, 90128 Palermo, Italy ${ }^{2}$ Dipartimento di Ingegneria Civile, Ambientale, Aerospaziale, \\ dei Materiali, (DICAM) settore Geomotica, Università di Palermo, Facoltà di Ingegneria, Viale delle \\ Scienze Ed. 8, 90128 Palermo, Italy ${ }^{3}$ Dipartimento di Ingegneria Chimica, Informatica, Gestionale, \\ Meccanica, (DICGIM), Università di Palermo, Facoltà di Ingegneria, Viale delle Scienze Ed. 8, \\ 90128 Palermo, Italy
}

\begin{abstract}
The Common Agricultural Policy of the European Union grants subsidies for olive production. Areas of intensified olive farming will be of major importance for the increasing demand for oil production of the next decades, and countries with a high ratio of intensively and super-intensively managed olive groves will be more competitive than others, since they are able to reduce production costs.

It can be estimated that about $25-40 \%$ of the Sicilian oliviculture must be defined as "marginal". Modern olive cultivation systems, which permit the mechanization of pruning and harvest operations, are limited.

Agronomists, landscape planners, policy decision-makers and other professionals have a growing need for accurate and cost-effective information on land use in general and agronomic parameters in the particular. The availability of high spatial resolution imagery has enabled researchers to propose analysis tools on agricultural parcel and tree level.

In our study, we test the performance of WorldView-2 imagery relative to the detection of olive groves and the delineation of olive tree crowns, using an object-oriented approach of image classification in combined use with LIDAR data.

We selected two sites, which differ in their environmental conditions and in their agronomic parameters of olive grove cultivation. The main advantage of the proposed methodology is the low necessary quantity of data input and its automatibility. However, it should be applied in other study areas to test if the good results of accuracy assessment can be confirmed.

Data extracted by the proposed methodology can be used as input data for decision-making support systems for olive grove management.
\end{abstract}

Keywords: Multiresolution segmentation, Nearest Neighbour classification, tree crown detection, NDVI, World View-2, LIDAR

Remote Sensing for Agriculture, Ecosystems, and Hydrology XVI, edited

by Christopher M. U. Neale, Antonino Maltese, Proc. of SPIE Vol. 9239, 92391F

(C) 2014 SPIE · CCC code: 0277-786X/14/\$18 - doi: 10.1117/12.2065952

Proc. of SPIE Vol. 9239 92391F-1 


\section{INTRODUCTION}

Traditionally, land use classification was carried out by manual polygon delineation on orthophotos which, however, is expensive, time-consuming and, to a certain degree subjective. With the availability of satellite imagery, unsupervised and supervised classification techniques became a valid alternative to manual interpretation. However, the first approaches were pixel-oriented, i.e. carried out on a pixel-basis, and did not recognize certain land use classes. Moreover, the increase of spatial resolution of the imagery created problems, because the higher the spatial resolution the higher is also the potential within-class heterogeneity of pixel values.

In the last decade, object-oriented approaches have been developed as valid techniques for land use classification. These are not based on single pixels, but on objects which are produced by image segmentation, performed by specific algorithms, which partition an image into regions (objects) based on homogeneity or heterogeneity criteria. Land use classes can be assigned to the resulting image objects based on their spectral, spatial, structural and textural characteristics, increasing, thus, the amount of criteria used for classification. Object-oriented classifications of highresolution panchromatic (PAN) and multispectral (MS) data have been successfully applied for general land use classification [1], and for specific applications in forestry and agriculture, such as for example for landscape feature mapping [2], extraction of regularity patterns in orchards [3], and olive tree extraction [4].

Apart from the extraction of land use classes, object-oriented techniques can also be used for single tree canopy delineation. Agronomic applications need to work on tree level, and the increase of spatial resolution of satellite imagery in the last decade has enabled researchers to develop methods for tree canopy detection. Multispectral sensors have the additional advantage of recording separately the Visible Red (R) and the Near Infrared (NIR) band, which are important for vegetation mapping [5].

There are several methods which have been studied for automatic tree delineation, such as local spatial maxima definition, valley following and clustering $[5,6]$. All methods have to face the problems of tree canopy overlapping, the small size of young trees, the analysis of pixels with mixed reflectance of soil and tree, and the internal heterogeneity of spectral information of trees and background.

Object-oriented techniques which combine the use of multispectral satellite data with other ancillary data, such as LIDAR data, are even more promising [7, 8, 9].

LIDAR (LIght Detection And Ranging) is an optical remote-sensing technique which uses laser light to produce clouds of points with three-dimensional coordinates. For every point, additional information, such as the intensity and the number of returns of every laser pulse, is stored. Vegetation height can be obtained from LIDAR data, and LIDAR data have been explored by forest researchers to detect tree height, delineate single trees, define forest stand structure and estimate biomass and wood volume [10,11]. LIDAR data have also been used in combination with multispectral or panchromatic imagery for the creation of land use maps [7,9].

Most of these studies have used Quickbird or Ikonos imagery, while the more recent imagery of WorldView-2 (WV2) still has to be explored. Apart from a slightly higher spatial resolution (0.6 and $0.5 \mathrm{~m}$ in PAN and 2.5 and $2 \mathrm{~m}$ in MS in Quickbird and WorldView-2, respectively), WV2 imagery possesses four additional spectral bands. 
This study intend to test the performance of WorldView-2 imagery relative to the detection of olive groves and the delineation of olive tree crowns

\section{MATERIALS \& METHODS}

\subsection{Study area}

The study has been carried out using an object-oriented approach of image classification in combined use with LIDAR data recorded in 2011 in Sicily, Italy. In this region olive groves represent 10\% of the total agricultural land use [12]. The territorial heterogeneity of Sicily has determined the development of a large variety of olive grove models which differ in soils types, topographic traits, cultivars, tree planting density, orchard layout, tree shape and pruning systems [13]. It can be estimated that about $45 \%$ of the Sicilian olive grove should be defined as "marginal", as they are characterized by irregular planting layout, low tree planting densities, high percentage of old trees or trees hardly damaged by pathogens. Estimate of modern olive grove, in which mechanization of pruning and harvesting could be performed, are limited to no more than $10 \%$ of the Sicilian olive grove [14].

To carry the study have been selected two areas: Sciacca, within the province of Agrigento and San Mauro, in the province of Messina. The chosen of the above mentioned areas has been mainly determined by deep differences in tree planting designs, average planting age, soils morphology and, consequently, the horticultural management of the groves.

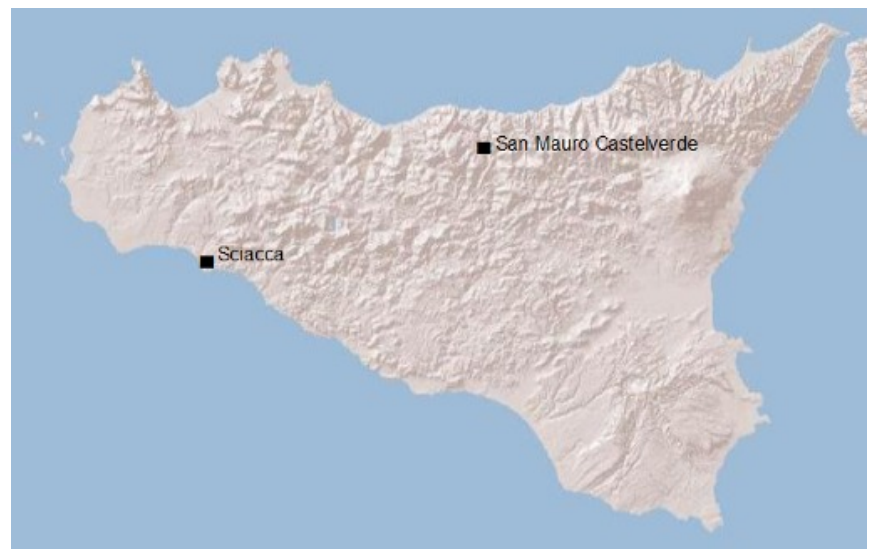

Figure 1. Study areas

The territory of "Sciacca" located South-west of Sicily (37, 30 Lat N), is mainly flat, and seldom interrupted by few valleys, created by short rivers and torrents (Figure 2). Soils are mainly Eutric Cambisols and Eutric Regosols, geological substrates are sandstone and alluvional deposits, and bioclimate has been classified as Thermomediterranean Upper Arid. Olive groves are mainly traditional monocultural systems, shoving regular tree spacing or polycultural systems of olive associated with vineyard or, less frequently, fruit or orange trees. 


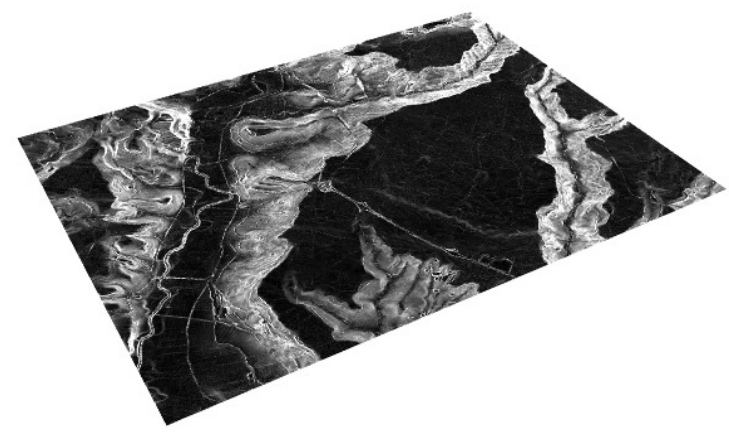

Figure 2. Map of slopness ( Sciacca area)

"San Mauro" area is located North-west of the Island and is characterized by hilly and mountainous geomorphology, slope inclination often is superior to 25\% (Figure 3). Soils are mainly Eutric and Leptic Cambisols, geological substrate are sandstones and arenaceous marls, and in a river valley alluvional sediments. Bioclimate has been classified as Mesoand Thermomediterranean - Upper and Lower Subhumid. Here, olive groves are mainly characterized by an irregular tree spacing, and frequently mixed systems with Mediterranean, rainfed fruit trees, or tree species used for agroforestry.

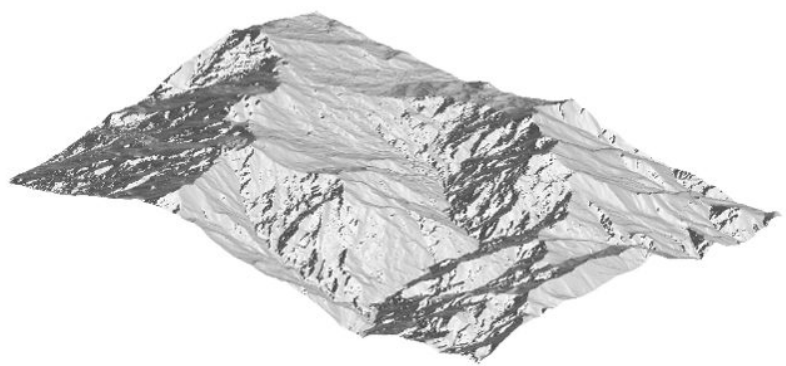

Figure 3. DEM (S. Mauro area)

\subsection{Imagery and LIDAR data}

Multispectral and panchromatic mode of two Worldview-2 scenes were acquired, covering $25 \mathrm{~km}^{2}$ in the Sciacca (acquisition date 25/08/2011) and San Mauro (acquisition date 30/09/2011) sites, respectively. Spatial resolution was 2 $\mathrm{m}$ in MS and $0.5 \mathrm{~m}$ in PAN. MS covered 8 bands (Red, Green, Blue, NIR1, Coastal, Yellow, Red Edge, NIR2). The scenes were delivered in 16 bit per pixel.

LIDAR data had a raw point density of 1.5 points $/ \mathrm{m}^{2}$. It was recorded with an ALTM Gemini and Pegasus sensor on behalf of the Italian Ministry for Environment [15]. Point coordinates were delivered with additional information on the first and last return, and the intensity of the echo. The first return of the LIDAR pulse is the one reflected by object surfaces above the ground surface (vegetation, buildings, etc.), while the last return is the one reflected by the ground surface. Intensity, on the other hand, provides an information about the strength of the returned laser pulse, which is determined by the reflectivity of the object surface. For Sciacca, have been used three LIDAR strips recorded on 
12/05/2011 and seven strips recorded on 18/03/2012, while for San Mauro have been used 25 strips recorded on $12 / 05 / 2011$.

\subsection{Ground truth data sampling}

In both sites within the scene covered by the acquired WV2 images were selected four areas of $1 \mathrm{x} 1 \mathrm{~km}$. Within these sites, has been carried out a manual polygonization of the following land use classes: 1) cultivated, monocultural olive groves. 2) cultivated, polycultural olive groves together other fruit trees and/or agroforestry tree species. 3) abandoned olive groves 4) other cropland 5) riparian vegetation 6) buildings \& infrastructures.

In spring 2013, has been conducted a land use survey to control the attributed land use classes; minimum area of the resulting land use maps was 15 x 15 m. Land use maps were created in ArcGIS 10 (ESRI), using the PAN band of WV2. Moreover, in both sites 20 olive groves were selected as sampling sites on a parcel level. Cultivated as well as abandoned, and groves with regular tree spacing as well as irregular tree spacing were chosen. Each site included about fifty olive trees. Tree canopy were delineated as single polygons in ArcGIS.

In addition, during a further land survey have been collected data on tree canopy diameter and tree height in three sampling sites in Sciacca and in two sampling sites in San Mauro. In Sciacca, two of these groves were characterized by a regular tree spacing (SCO1 and SCO2), and one by an irregular tree spacing (SCO3); all groves were regularly cultivated (Figure 4).

In San Mauro, both sites were characterized by an irregular tree spacing (Figure 5), one cultivated (SM01) and one abandoned (SM02).

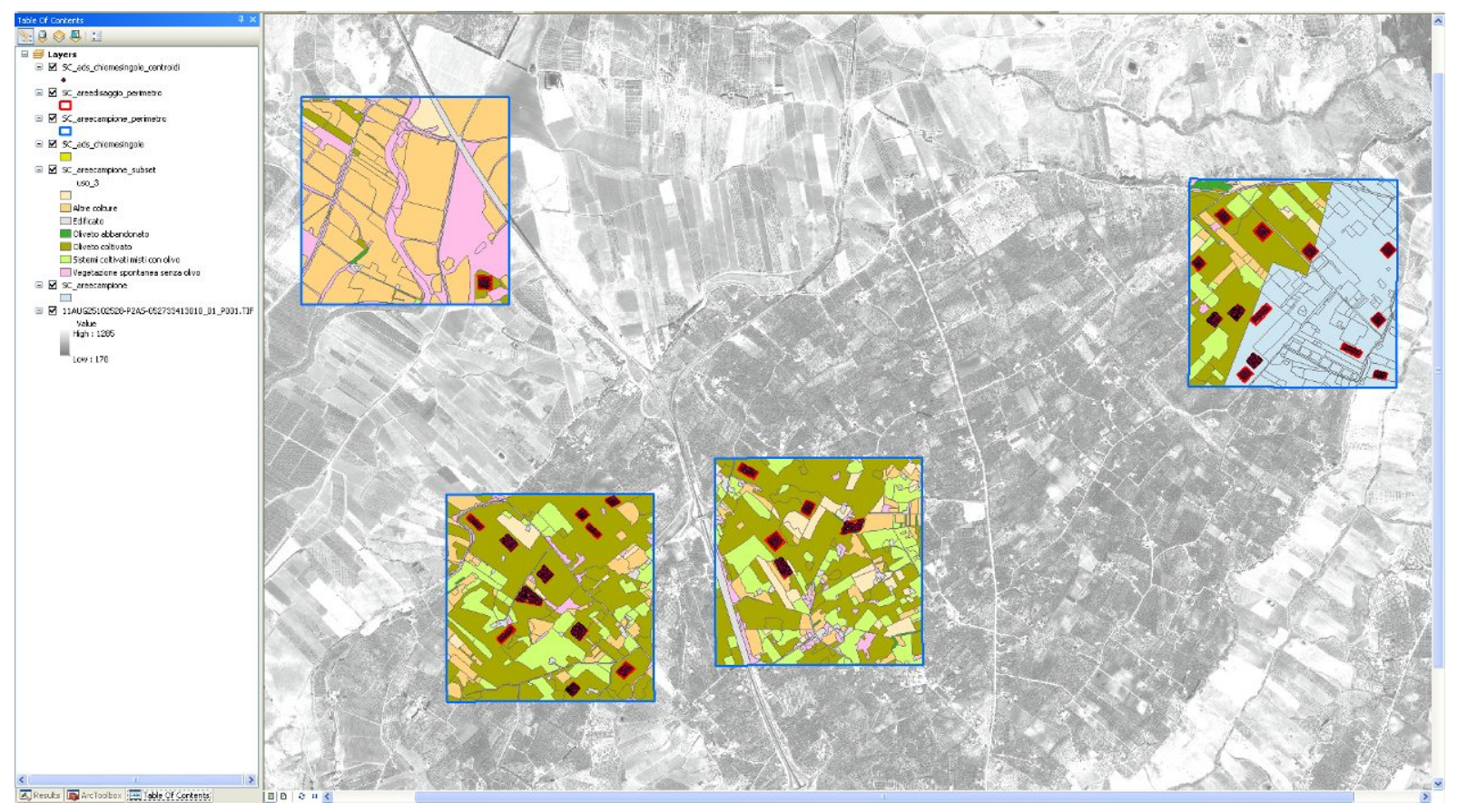

Figure 4. Sampling parcels (Sciacca area) 


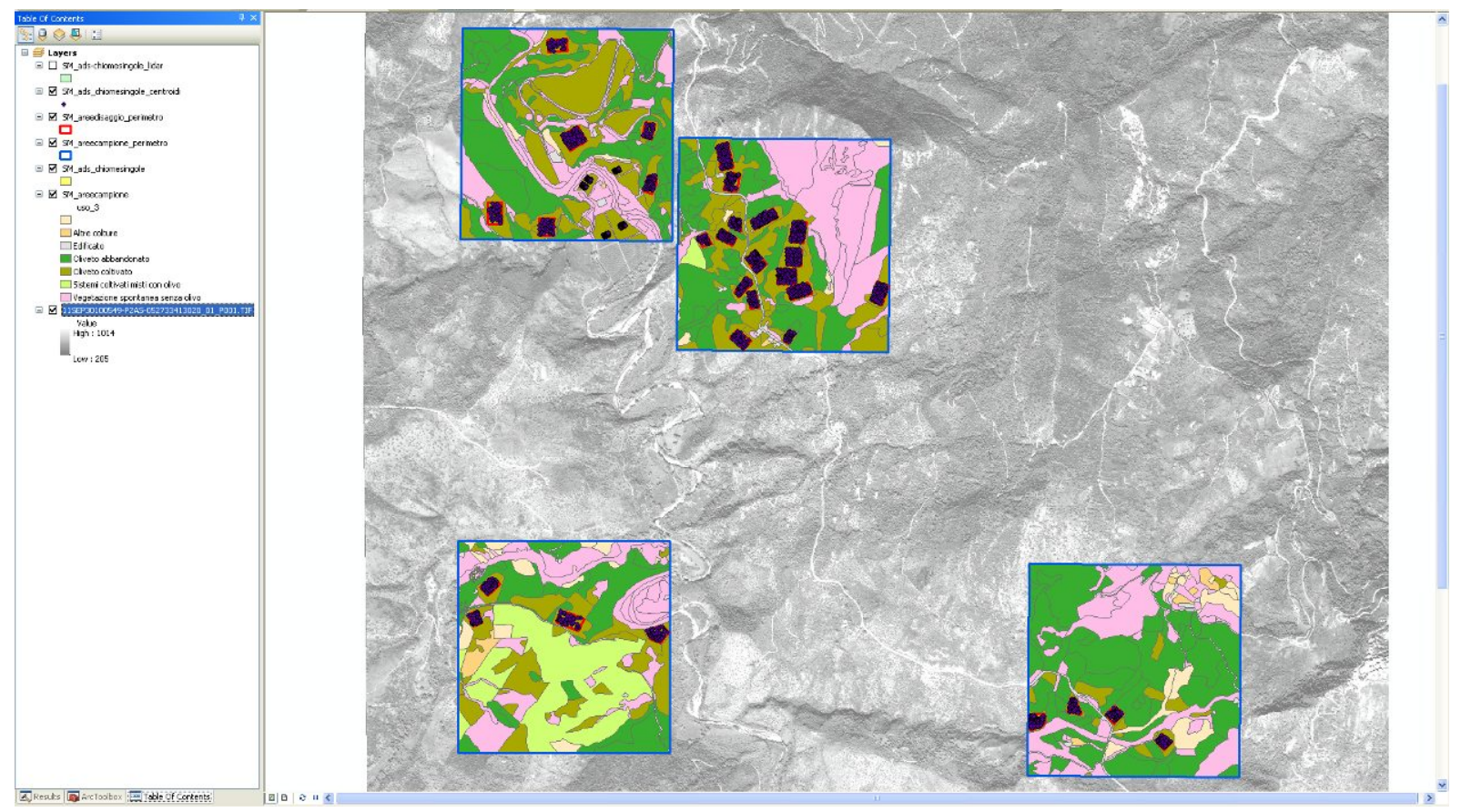

Figure 5. Sampling parcels (San Mauro area)

\subsection{Olive grove and olive tree canopy detection}

In the first phase of the study we had used a pixel oriented classification (supervised), but because of the heterogeneity of the pixel values in each class we had obtained a percentage of accuracy that is not acceptable.

In the transition to object-oriented method has been crucial the choice of criteria to be used in classification. The segmentation was initially performed with the exclusive use of the images and data layers derived from them. The method, however, needed additional layers of information for a good delineation of olive tree crowns, for this reason it has been used Canny edge algorithm for the extraction of the contours of the objects.

Multiresolution segmentations and nearest neighbour classifications of a two steps approach was performed. In the first step, which had the aim to detect olive groves, a coarse segmentation was applied, and the resulting image objects were then classified by the use of typical objects as representative samples into olive groves and non-olive groves. In the second step, the objects classified as olive groves within the first step were re-segmented applying a finer segmentation, and then classified again by the use of representative training samples, into olive trees and bare soil. After these classifications, has been carried out a detailed assessment by using ground reference data (Figure 6). 


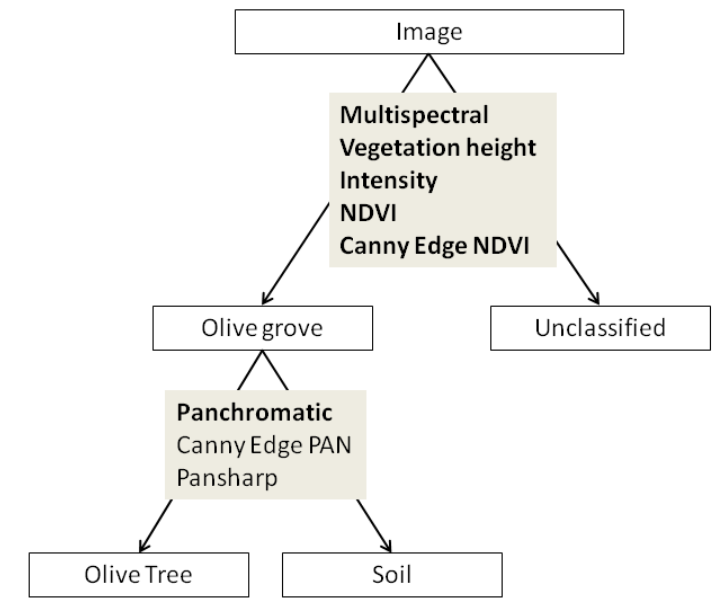

Figure 6. Rule sets

Segmentation and classification operations were carried out with eCognition 8 software (Trimble). For analyses were employed raw spectral data from the WV2 image and raw LIDAR data and pre-processed WV2 and LIDAR data. The following sections explain more in detail the single steps of data elaboration.

\subsection{Data pre-processing}

Step 1. Precise georeferencing and overlapping of all data layers was assured. Step. 2 Pansharpening of MS and PAN was carried out using HCS resolution merge.

Step 3. Normalized Difference Vegetation Index (NDVI) was computed from the R and NIR band of the MS mode of the WV2 image. The NDVI which is calculated on a per-pixel basis as NDVI $=(\mathrm{NIR}-\mathrm{R}) /(\mathrm{NIR}+\mathrm{R})$, is an index that is extensively used for vegetation mapping. Living green plants absorb solar radiation in the Visible Red region, while they reflect in the NIR region. As a consequence, the presence of a healthy vegetation results in high NDVI values, while the absence of vegetation results in low NDVI values. After NDVI calculation, linear stretching and histogram equalization have been applied for contrast enhancement on the resulting image layer.

Step 4. By using eCognition has been conducted a Canny Edge extraction operator on the NDVI image. Edge extraction operators are used to extract feature boundaries, because they highlight regions of strong pixel value changes in images. In this case, the aim was to enhance the delimitation of olive parcels by exploiting the information contained in the NDVI layer. Lower and higher threshold were defined as " 0 ", width of the Gaussian filter was set to " 5 ". In addition, the Canny Edge extractor was applied to the PAN image in order to support tree canopy delineation. Here, lower threshold was set to "0", higher threshold was set to " 0.22 ", and Gaussian filter was set to " 1 ".

Step 5. Calculation of vegetation height, which is a very useful parameter for land use classification. Raw LIDAR data strips have been loaded in eCognition, and extracted the average value of the first return and the average value of the last return for each pulse using the "LIDAR File Converter" algorithm. The resulting Digital Elevation Model (DEM, from first return) and Digital Surface Model (DSM, from last return) were exported to ArcGIS, where we subtracted DEM from DSM to obtain vegetation height by using the "Spatial Analyst - Minus" tool. Then, the single strips were merged 
with the "Data Management - Mosaic" tool, and vegetation height raw data was reclassified into the following five classes by using the "Spatial Analyst - Reclassify" tool: 1) 0-0.1 m; 2) 0.01-0.5 m; 3) 0.5-1.5 m; 4) $1.5-4 \mathrm{~m}$; 5) $>4 \mathrm{~m}$. Moreover, echo intensity was extracted from LIDAR data in eCognition for the detection of vegetation. Afterwards was applied a median filter with a kernel size of " 3 " to remove salt and pepper-noise, and used histogram normalization to stretch pixel values to the entire pixel value range for contrast enhancement [9].

\subsection{Segmentation \& Classification}

Segmentation starts with one-pixel objects, which are in several subsequent steps merged to bigger objects until userdefined heterogeneity criteria are met [2]. Multiresolution segmentation in eCognition requires the following userspecified parameters: 1) scale; 2) shape; 3) compactness; 4) relative weights of input layers.

The scale parameter defines the threshold for object merge with respect to the size of the objects. The higher the scale parameters, the bigger the resulting objects. The shape parameter defines the degree of the use of geometric heterogeneity for object merge. When it is set to "1", objects are defined exclusively by their spatial characteristics, while when it is set to " 0 ", only spectral heterogeneity is used for object definition. Within the spatial characteristics, the compactness parameter defines if more weight should be given to compactness or to smoothness in object definition.

For the first step of image segmentation (= "level 2"), the one aiming at the detection of olive groves, have been loaded as image layers in eCognition the $8 \mathrm{MS}$ bands of the WV2 image, the reclassified vegetation height data, LIDAR intensity data, the NDVI layer, and the canny edge extraction layer derived from NDVI. Then, the algorithm "multiresolution segmentation" was applied on the pixel level. Since aim was to create quite large objects, which could represent agricultural parcels, has been applied a scale parameter of " 220 ". Shape parameter was set to " 0.5 ", and compactness parameter was set to " 0.95 ". Equal weights were assigned to all image layers.

After image segmentation, ground truth data was used for the definition of ten image objects as positive samples for the class „olive grove“. Then, a nearest neighbour (NN) classification of level 2 image objects was computed using mean values of all input layers as discriminant features in the classes' feature space definition. No samples were defined for other land use classes.

Afterwards has been applied a second step of image segmentation (= "level 1"), which aimed at the delineation of olive tree canopy. As additional layers have been loaded in eCognition the PAN band of the WV2 image, the pansharpened bands, and the canny edge extraction layer derived from PAN band. Then, all image objects which in the previous step had been classified as „olive groves“ were re-segmented, applying a multiresolution segmentation algorithm with a very low scale parameter of " 5 ", a shape parameter of 0.7 , a compactness parameter of 0.5 , and equal weights to all image layers. After this re-segmentation, ground truth data was used to identify twenty image objects as positive samples for the class „olive tree“, and twenty as positive samples for the class „,bare soil“. Then, NN classification of level 1 image objects was computed using as the only discriminant feature the mean object value of the PAN band“, because all other features showed too much overlapping in their membership functions. The layers set in red bold in the below images are the ones which were not only used for segmentation, but also for the definition of membership functions during nearest neighbour classification (Figure 7, Figure 8). 


\subsection{Accuracy assessment}

The quality of olive grove detection and olive tree delineation was evaluated by exporting the level 1 and 2 classifications from eCognition in shape-format to ArcGIS. Level 2 classification ( 2 classes: olive grove; unclassified) was compared to land use data from the four ground truth areas in each site (6 classes: cultivated, monocultural olive groves; cultivated, polycultural olive groves; abandoned olive groves; other cropland; riparian vegetation; buildings \& infrastructure). We chose 6 classes of land use, for the ground truth data, in order to find a correlation between the errors of classification and types of land use. The area of correctly classified, false positive (commission error) and false negative (omission error) pixels has been calculated.

False positive area represents the area classified erroneously as olive groves in eCognition corresponding to other land use classes in ground truth data. False negative area represents those olive groves present in ground truth data which have not been detected by the classification in eCognition.

Level 1 classification ( 2 classes: tree canopy, soil) was compared to ground truth data from the 20 selected sampling sites in Sciacca as well as in San Mauro (2 classes: tree canopy, soil). The above data have been used to calculate the number of correctly detected olive tree canopy, and also the correctly classified canopy area.

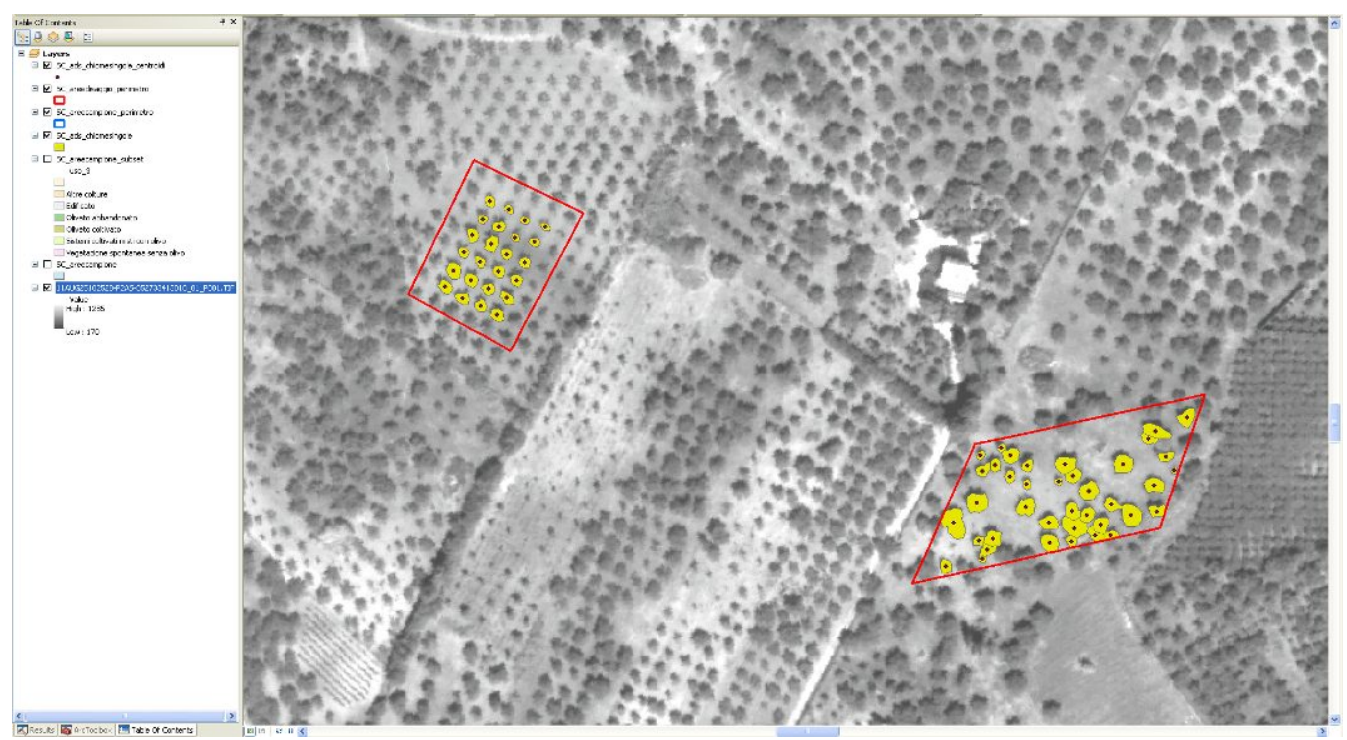

Figure 7. Canopy olive tree definition and tree centroids (Sciacca area) 


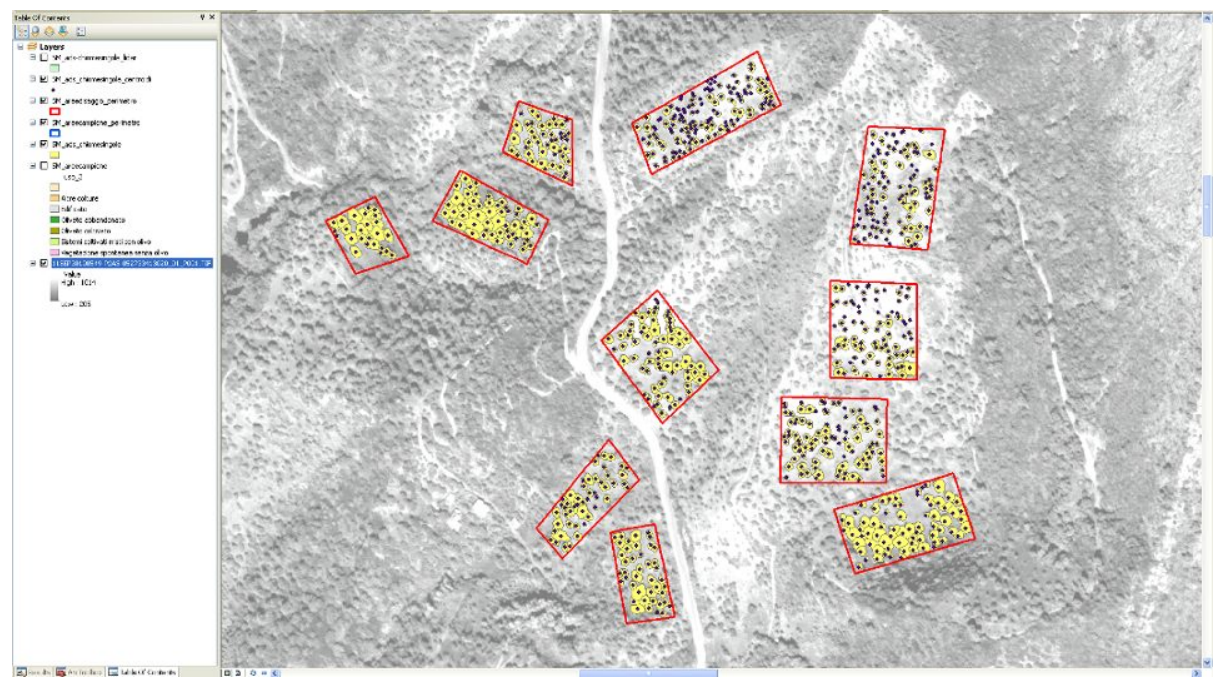

Figure 8. Canopy olive tree definition and tree centroids (San Mauro area)

\subsection{Extraction of Horticultural parameter}

From WorldView-2, LIDAR data and classification results we can extract several parameters that will be useful in decision support system that we are developing. For example, the geometric centroid was extracted for every parcel and for every olive tree canopy respectively, by application of the "Data Management - Feature to Point" tool in ArcGIS. To this aim has been used the level 2 image objects as parcels. Prior to tree canopy centroid extraction, overlapping canopies were separated by applying local maxima algorithms to the feature layer created from level 1 segmentation and classification. Agronomic parameters are listed in Tab. 1.

Tab. 1. Horticultural parameters extracted at parcel level.

\begin{tabular}{|l|l|l|}
\hline Denomination & Unit & Description \\
\hline Tree density & Nr. of trees/ha & First extract total number of trees per parcel, then divide by parcel area. \\
\hline Tree spacing & meters & $\begin{array}{l}\text { Compute average nearest neighbor with "Spatial Statistics - Analyzing } \\
\text { Patterns" tool. }\end{array}$ \\
\hline Slope & percentage & $\begin{array}{l}\text { Use DEM derived from LIDAR data to construct slope with the } \\
\text { "Spatial Analyst - Surface" tool, then compute "Zonal Statistics" with } \\
\text { "Spatial Analyst - Zonal" tool to calculate mean gradient for parcel. }\end{array}$ \\
\hline Mean tree height & meters & $\begin{array}{l}\text { Extract height of single olive trees by intersecting tree crown polygons } \\
\text { with LIDAR vegetation height data, selecting the maximum height } \\
\text { value for every crown. Then calculate the mean height from all trees } \\
\text { within a parcel. }\end{array}$ \\
\hline $\begin{array}{l}\text { Percentage of trees } \\
\text { higher than } 4.5 \mathrm{~m}\end{array}$ & percentage & $\begin{array}{l}\text { Count number of trees higher than 4.5 m and calculate as percentage } \\
\text { from all trees within a parcel. }\end{array}$ \\
\hline $\begin{array}{l}\text { Percentage of trees } \\
\text { higher than } 6 \mathrm{~m}\end{array}$ & percentage & $\begin{array}{l}\text { Count number of trees higher than } 6 \mathrm{~m} \text { and calculate as percentage } \\
\text { from all trees within a parcel. }\end{array}$ \\
\hline Olive crown density & meters & $\begin{array}{l}\text { Calculate single tree crown area, then suppose that tree crown has the } \\
\text { shape of a circle and calculate first crown radius } r \text { with } r=\sqrt{ }(\mathrm{crown} \\
\text { area/ } \pi \text { ) and then single tree diameter } d \text { as } d=2 r \text {; then calculate mean } \\
\text { tree diameter per parcel. }\end{array}$ \\
\hline
\end{tabular}


The accuracy of the measures of tree diameter and tree height derived from LIDAR data was evaluated in sample areas. In the image below (Figure 9) is resumed the workflow of data elaboration and validation.

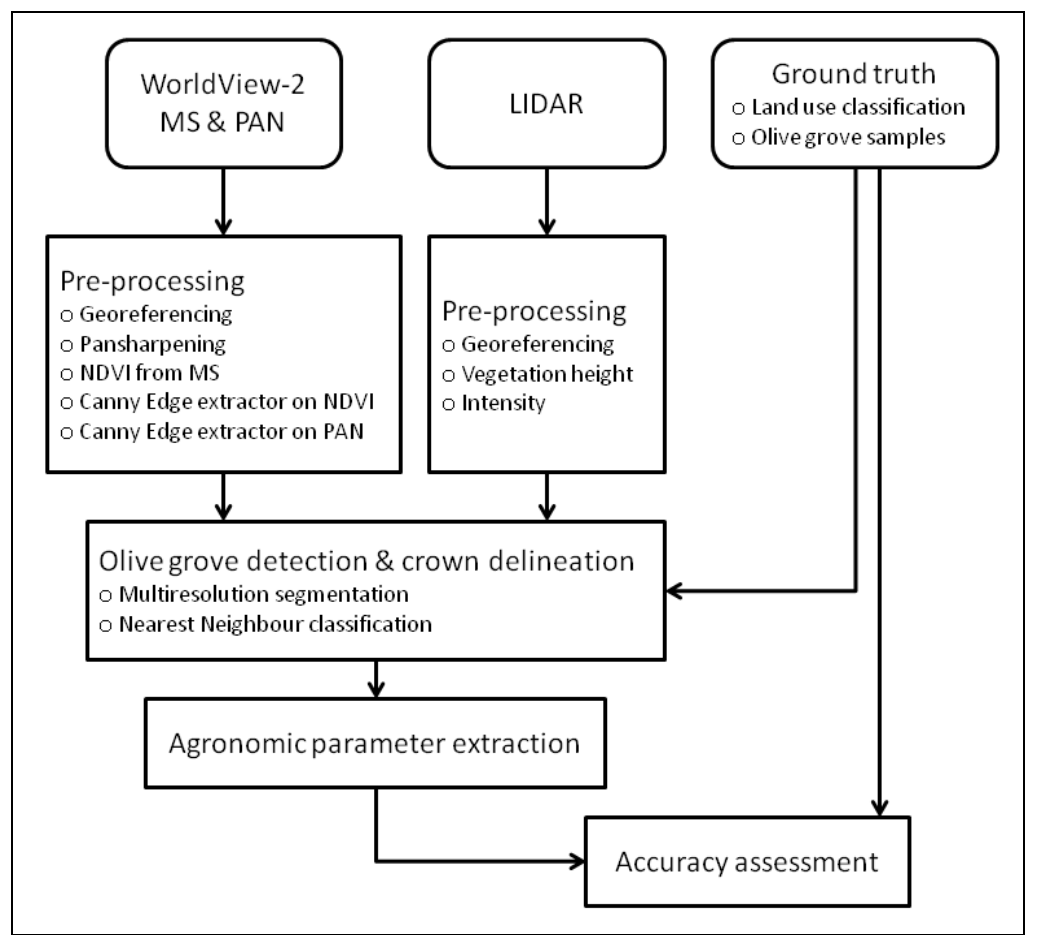

Figure 9. Workflow of data elaboration.

\section{RESULTS}

The present research demonstrates the ability of an advanced methodology in the developing an expert system for land use classification: the hybrid solution implemented in the software eCognition.

The methodology suggested has proved to achieve the main goals of olive grove detection and tree canopy delineation.

This method proved its potentiality combining different processes and good data imagery availability. The use of WorldView-2 imagery was successful, since was able to quantify within-field spatial variability of olive groves. Moreover, spatial variability in soil properties, caused by the presence of a patch of sandy soil, was also detected visually on the enhanced false colour imagery. The participation of ancillary data derived from LIDAR data and pre-processing of WorldView-2 data must be judged as very positive.

Olive grove detection with the proposed methodology gave quite good results (Tab. 2). Levels 2 classification (Figure 10) detected $89.0 \%$ of all present olive groves. While cultivated monocultural and polycultural olive groves gave good results, abandoned olive groves were poorly detected. The commission error (false positives) had an overall value of $15.0 \%$, with the highest error rates by other croplands, while riparian vegetation and infrastructure and buildings accounted for a low rate of false positives.

Proc. of SPIE Vol. 9239 92391F-11 


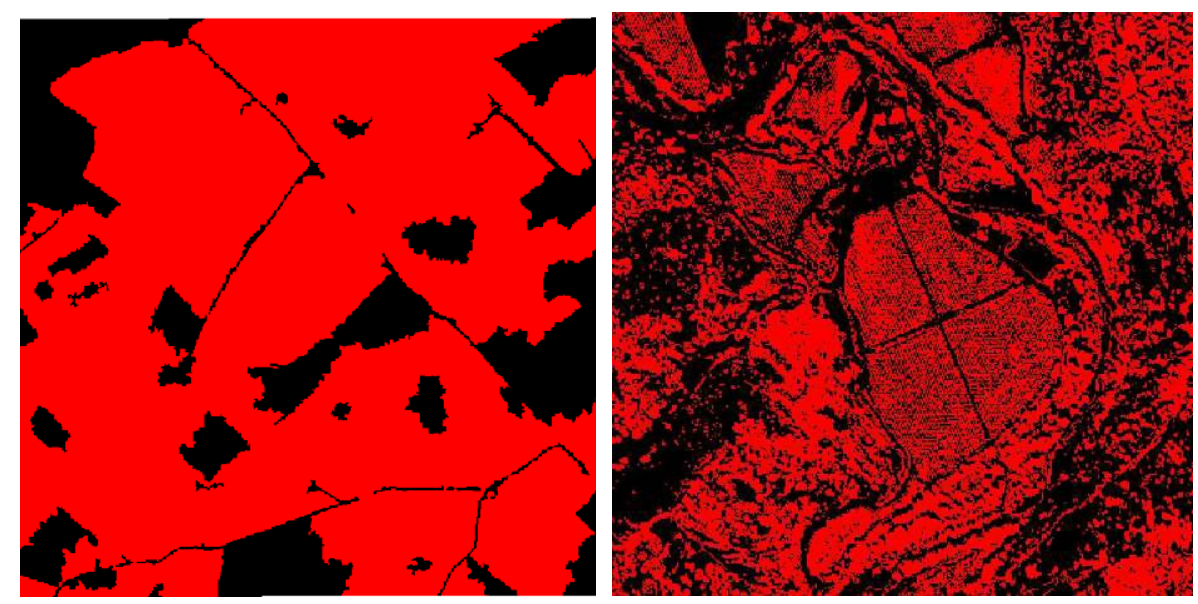

Figure 10. Level 2 classification of Sciacca area. (on the left) and San Mauro area (on the right).

(Olive grove $=$ red, Unclassified=black)

Tab. 2. Results of accuracy assessment.

\begin{tabular}{|c|c|c|c|}
\hline & & \begin{tabular}{|l} 
Sciacca \\
(Percentage)
\end{tabular} & \begin{tabular}{|l|} 
San Mauro \\
(Percentage)
\end{tabular} \\
\hline \multirow[t]{4}{*}{ Level 2} & Overall correct "olive grove present" & 89,0 & 83,0 \\
\hline & Overall false negative & 11,0 & 17,0 \\
\hline & Overall false positive & 15,0 & 18,0 \\
\hline & Overall correct "olive grove absent" & 85,0 & 82,0 \\
\hline \multirow{15}{*}{$\begin{array}{l}\text { Level } 1 \\
\text { (sampling areas) }\end{array}$} & OLIVE MONOCULTURE & & \\
\hline & Correct "olive grove present" & 89 & 83 \\
\hline & False negative & 11 & 17 \\
\hline & OLIVE POLYCULTURE & & \\
\hline & Correct "olive grove present" & 81 & 78 \\
\hline & False negative & 19 & 22 \\
\hline & OLIVE ABANDONED & & \\
\hline & Correct "olive grove present" & 53 & 51 \\
\hline & False negative & 47 & 49 \\
\hline & OTHER CROPLAND & & \\
\hline & False positive & 16,2 & 19,5 \\
\hline & RIPARIAN & & \\
\hline & False positive & 3,1 & 5,2 \\
\hline & BUILDINGS \& INFRASTRUCTURE & & \\
\hline & False positive & 0,9 & 1,3 \\
\hline
\end{tabular}

In terms of presence/absence, all trees (100\%) present in the olive grove sampling sites were detected by level 1 segmentation and classification (Figure 11). Also in terms of tree canopy area, the proposed method gave good results: in total, $90 \%$ of the overall tree canopy area was correctly classified. 


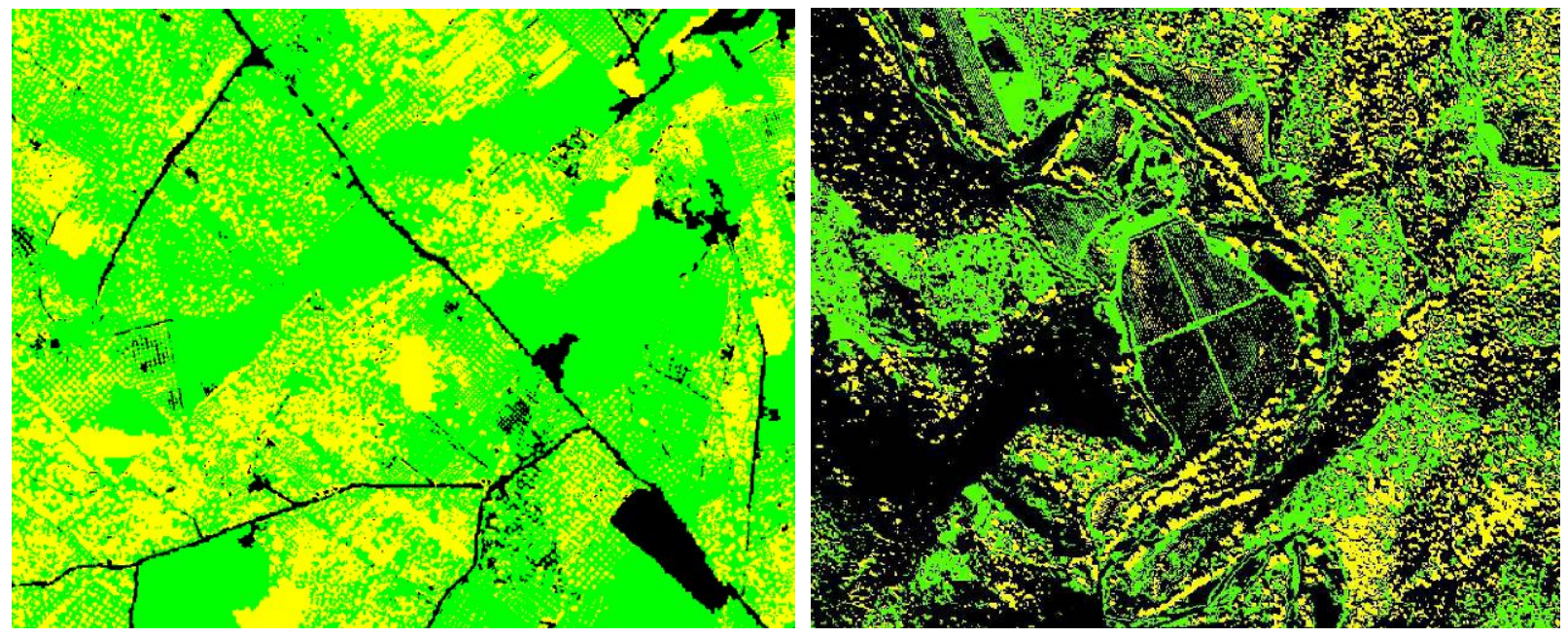

Figure 11. Level 1 classification of Sciacca area (on the left) and San Mauro area (on the right).

(Olive tree=yellow, Soil=green, Other=black)

\section{DISCUSSION}

The availability of high spatial resolution imagery has enabled researchers to propose analysis tools on agricultural parcel and to tree level [16].

More work is being done to develop image classification techniques for mapping within-field spatial variability in olive varieties, biomass and condition using hyperspectral image data [17].

Results of this research evidenced that high-spatial resolution Wordview2 imagery combined with LIDAR data was able to quantify within-field spatial variability of olive groves. The methodology proposed should be applied to other study areas to test if the good results of accuracy assessment can be confirmed.

Italy is the second olive tree growing country in the world [12]. Although within the total world production the Italian olive oil still account for $23,5 \%$, in the current context of production costs, the economic return of the growers is year by year decreasing and, consequently, they tend to abandon olive groves. The only strategy to counteract these tendency largely rely on the mechanization of harvest and pruning that, in turn, requires groves of limited slope, having a regular orchards layout and adequate tree distances for machinery circulation and trees properly shaped for the efficiency of machines in harvesting and pruning. Olive groves do not presenting the above mentioned characteristics should be considered marginal and devoted to multipurpose agriculture.

The identification and quantification of marginal olive groves becomes a major issue for the development of the olive industry, particularly for future olive oil grove planning. To this aim, developing an automatable methodology for olive grove detection, single tree delineation, and horticultural management systems characterization is a major prerequisite for the identification of marginal olive grove within large agricultural areas. The classification, on the base of agronomic parameters, of marginal olive grove will allow to development decision-making support models for olive groves management. Thematic layers produced in this research could be used as input data in decision-making support systems for olive grove management. 


\section{ACKNOWLEDGEMENTS}

This paper was carried out under the project DIMESA_PON02_00451_3361785 (project manager: prof. Tiziano Caruso).

\section{REFERENCES}

[1] Tarantino E., "Land cover classification of QuickBird multispectral data with an object-oriented approach", 4th International Conference on Management Information Systems Incorporating GIS \& Remote Sensing. Management Information Systems, 8: 125-134 (2004).

[2] Karydas C.G., Sekuloska T., Sarakiotis I., "Fine scale mapping of agricultural landscape features to be used in environmental risk assessment in an olive cultivation area", IASME Transactions, 4 (2): 582-589 (2005).

[3] Ruiz L.A., Recio J.A., Hermosilla T., "Methods for automatic extraction of regularity patterns and its application to object-oriented image classification", International Archives of the Photogrammetry, Remote Sensing and Spatial Information Sciences, 36 (3), W49A (2007).

[4] Karantzalos K., Argialas D., "Towards the automatic olive trees extraction from aerial and satellite imagery", International Archives of the Photogrammetry, Remote Sensing \& Spatial Information Sciences, 35 (5): 1173-1177 (2004).

[5] Daliakopoulos I.N., Grillakis E.G., Koutroulis A.G., Tsanis I.K., "Tree crown detection on multispectral VHR satellite imagery", Photogrammetric Engineering and Remote Sensing, 75 (10): 1201-1211(2009).

[6] Recio J.A., Hermosilla T., Ruiz L.A., "Automated extraction of agronomic parameters in orchard plots from high-resolution imagery", The use of remote sensing and geographic information systems for irrigation management in Southwest Europe, CIHEAM, 161-174 (2012).

[7] Viñas O., Ruiz A., Xandri R., Palà V., Arbiol R., "Combined use of Lidar and Quickbird data for the generation of land use maps", ISPRS Mid-term Sysposium "From Pixels to Processes". Enschede, 8-11 May, 2006 (2006).

[8] Corona P., "Integration of forest inventory and mapping to support forest management", iForest Biogeosciences and Forestry, 3: 59-64 (2010).

[9] Wang A., Zhao S., Zhou H., Luo Y., Tan L., "Object-based classification using LiDAR-derived metrics and QuickBird imagery", Earth Observation and Remote Sensing Applications (EORSA), 2012 Second International Workshop, 8-11 June 2012, 181-185 ( 2012).

[10] Mei C., Durrieu S., "Tree crown delineation from digital elevation models and high resolution imagery", Proceedings of the International Archives of the Photogrammetry, Remote Sensing and Spatial Information Sciences, 36 (2004).

[11] Koch B., Heyder U., Weinacker H., "Detection of individual tree crowns in airborne lidar data", Photogrammetric Engineering and Remote Sensing, 72 (4) (2006).

[12] ISTAT website. URL http://dati-censimentoagricoltura.istat.it. Last Access: 01.12.2013.

[13] Caruso T., Cartabellotta D., Motisi A., Campisi G., Occorso G., Bivona G., Cappello A., Pane G., Pennino G., Ricciardo G., Patti M., La Mantia M., Lain O., Testolin R., Finoli C., Cacioppo L., Corona O., Catagnano L., Savino V., Saponari M., "Cultivar Di Olivo Siciliane. Identificazione, validazione, caratterizzazione morfologica e molecolare e qualità degli oli”, Palermo, Dipartimento Colture Arboree, Regione Siciliana, 1-202 (2007).

[14]FAOSTAT website. URL http://faostat.fao.org. Last Access: 01.12.2013.

[15] Geoportale nazionale website. URL http://www.pcn.minambiente.it/GN/ Last Access: 20.03.2014.

[16] Selim Aksoy, Ismet Zeki Yalniz, Kadim Tasdemir, "Automatic Detection and Segmentation of Orchards Using Very High Resolution Imagery”, IEEE T. Geoscience and Remote Sensing 50(8): 3117-3131 (2012).

[17] Apan, Armando and Young, Frank R. and Phinn, Stuart and Held, Alex and Favier, Jason. "Mapping olive varieties and within-field spatial variability using high resolution QuickBird imagery", Proceedings of 12th Australasian Remote Sensing and Photogrammetry Conference, Spatial Science Institute (2004). 